\title{
CORRESPONDENCE
}

\section{OPHTHALMOLOGICAL RE-ORGANISATION}

\section{To the Editors of The BRItish Journal of Ophthalmology.}

DEAR SIRS, - No members of the ophthalmological community are more interested in the impending re-organisation of their speciality than are Service ophthalmologists abroad.

The Army ophthalmologists consist of a considerable number of established specialists, junior specialists with special qualifications, and trainees who intend to become full time ophthalmologists after the war.

Travel abroad has widened their outlook and matured their judgement, and as many have visited foreign clinics they are in a strong position to assess the advantages and disadvantages of British ophthalmology as it is at present conducted.

Their professional capital has become greater than that of their counterparts in civil life. The only eye diseases of civil life which are not treated to any great extent in the Army are cases of senile cataract and adult glaucoma. Otherwise, military ophthalmology on a battlefront abroad offers a far wider scope for ophthalmic experience and improvement of operative skill than can be obtained in civil practice at home. In addition, there is the close and valuable association gained by many military ophthalmologists with maxillo-facial and neuro-surgeons.

For these reasons, the opinion and advice of these men will be of value in shaping future policy and representation. Moreover, they have earned the right to participate in such deliberations.

It may seem more difficult than it actually is to obtain their views from abroad. All that is required is for the Organising Secretaries to. write by Air Letter to the Advisers in Ophthalmology of the respective Forces abroad. The Adviser will do the rest; he always knows the precise locations of his ophthalmologists and can readily pass on information. Surface mail and journals are not satisfactory means of disseminating information; still further delay is caused by changes of address inseparable from operational requirements.

A great opportunity for re-organisation and unity in the oph thalmic profession presents itself-but all classes must be fairly represented if such re-organisation is to be universally respected and fully effective.

Yours faithfully,

B. W. RYCROFT, Lt.-Col., R.A.M.C. Adviser in Ophthalmology, A.F.H.Q. 